\title{
Endoscopic Treatment of Sessile Colorectal Polyp
}

\author{
Fawzy. M. Mustafa \\ Department of General Surgery, Faculty of Medicine - Al-Azhar University \\ Cairo - Egypt \\ Correspondence to: Fawzy. M. Mustafa; Telephone number: (+20)01033319730, 00966548951348; \\ Email: fawzymetwallymustafa@gmail.com
}

\begin{abstract}
Background: Endoscopic resection of sessile colonic polyps' presents a number of unique challenges. Large sessile polyps are associated with the greatest risk of postpolypectomy bleeding, perforation and polyp recurrence, with massive submucosal scarring making subsequent attempts at endoscopic resection problematic.

Objective: This study aimed to evaluate feasibility, safety, and the effectiveness of endoscopic treatment of colorectal benign-appearing polyps.

Patients and methods: This prospective study was carried out on forty (40) consecutive patients at General Surgery Department, Al-Azhar University Hospitals, Cairo, Egypt between January 2014 and August 2016. All patients were subjected to clinical evaluation including history taking, general examination, abdominal and per-rectal examinations. Results: Of the 40 cases with removed polyps, 10 cases were excised by cold biopsy forceps, 4 cases were excised by cold snare, 12 cases were excised by hot snare and 14 cases were excised by EMR with mucosal lifting according to the size of the polyp. Complications included nonspecific abdominal pain in 5 patients (12.5\%) that were treated conservatively and bleeding in $3(7.5 \%)$, two cases during procedure while 1 case presented $7^{\text {th }}$ day post procedure. One case transferred into open surgery due to perforation. All cases were treated endoscopically. Post-polypectomy surveillance permitted the detection and treatment of recurrent polyps in 3 cases that treated endoscopically with piece meal excision.
\end{abstract}

Conclusion: This study showed that polypectomy of benign sessile colorectal polyps performed by an expert endoscopist is feasible, effective, and safe, even on an outpatient basis.

Keywords: Endoscope Polypectomy sessile polyps EMR (Endoscopic Mucosal Resection).

\section{INTRODUCTION}

Colon polyps are protrusions occurring in the colon lumen most commonly sporadic or with syndromes. Incidence of colorectal polyps increases with age. A prevalence of $30 \%$ in the people over the age of 50. The majority of benign neoplasms detected at screening colonoscopy is small and removed easily with widely employed biopsy and snare polypectomy techniques ${ }^{(\mathbf{1})}$. Paris classification divides polyps into different types based on morphology. It is considered as reference point for polyp definition as well as endoscopic resection ${ }^{(2)}$.

During colonoscopy, several factors determine whether a polyp is best suited for endoscopic removal vs surgical removal. Size is important when considering endoscopic resection. However, large size alone is no longer a contraindication for endoscopic removal ${ }^{(3)}$.

A large, sessile, nonpedunculated lesion is associated with higher rates of high-grade dysplasia and carcinoma and has challenges for endoscopic eradication. Endoscopic mucosal resection (EMR) is used as minimally invasive curative resection of benign and early-stage (T1a) malignant lesions throughout the gastrointestinal tract ${ }^{(4)}$.

\section{AIM OF THE WORK}

This study aimed to evaluate feasibility, safety and the effectiveness of endoscopic treatment of colorectal benign-appearing polyps.

\section{PATIENTS AND METHODS}

This prospective study was carried out on forty (40) consecutive patients at General Surgery Department, Al-Azhar University Hospitals, Cairo, Egypt between January 2014 and August 2016. All patients were subjected to clinical evaluation including history taking, general examination, abdominal and per-rectal examinations.

\section{Laboratory investigations:}

Complete blood count, prothrombin time $\&$ activity, INR, liver and kidney functions and fasting and postprandial blood glucose level.

Imaging evaluation included: Trans abdominal ultrasonography, barium enema and computerized tomography (if indicated). 
Ethical approval and written informed consent: An approval of the study was obtained from AlAzhar University Academic and Ethical Committee. Every patient signed an informed written consent for acceptance of the operation.

\section{Inclusion criteria:}

- All sessile polyps in the colon found during colonoscopy.

- $\geq 18$ years old.

\section{Exclusion criteria:}

Risk factors for submucosal invasion with Paris classification (0-IIa/c) morphology that corresponds to a flat lesion with a depressed component and a Kudo pit pattern (type V) corresponding with amorphous, irregular pits. Predictors for failed EMR including lesions of the ileocecal valve and those in a difficult position for resection. Pathological exclusion included invasive adenocarcinoma that necessitates a laparoscopic oncologic resection, polyps located in the distal $5 \mathrm{~cm}$ of the rectum that are most amenable to transanal surgical resection and sessile lesions associated with ulcerative colitis.

Procedures: It is performed as day case using sedations as midazolam and pethedine with preoperative bowel preparation.

\section{Endoscopic Mucosal Resection (EMR) with mucosal lifting.}

The injection needle approaches the target lesion at an angle, with the aim of entering the submucosal plane. A deeper, more perpendicularly oriented injection typically will find the muscle layer, and will not achieve an adequate lift. Submucosal injection agents include hyaluronic acid, hetastarch, and dextrose water, hypertonic saline, hydroxypropyl methylcellulose and even the patient's own blood but in this study Saline was used in injection and lifting.

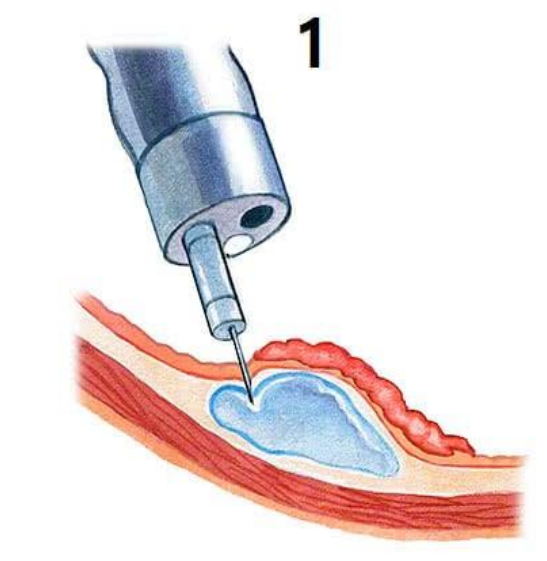

Injection of fluid to lift polyp

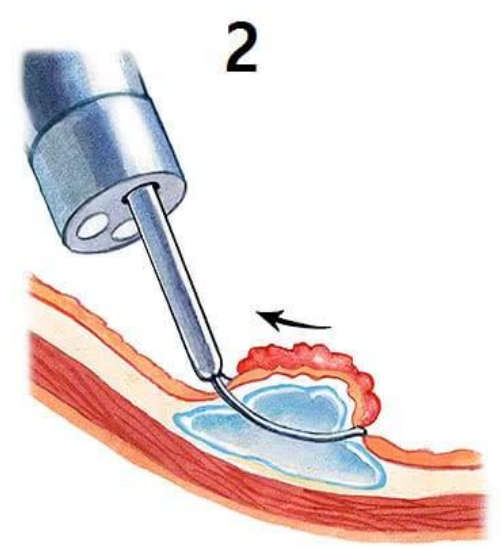

snared removal of polyp

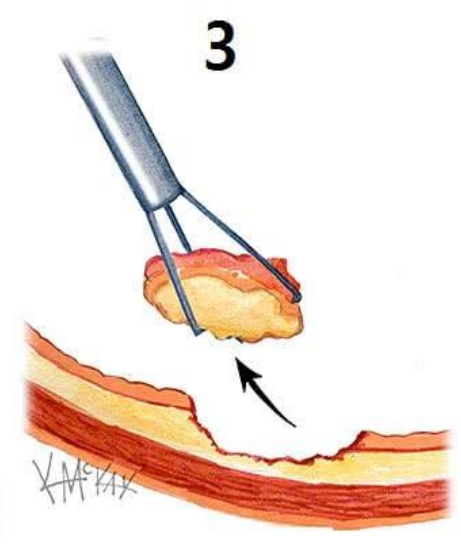

retrieval with forceps

Figure (1): Mechanism of EMR with mucosal lift.

\section{Cold snare procedure}
(A) Snaring of the polyp with 1-2 $\mathrm{mm}$ rim of normal tissue around it.
(B) Fully closing the snare and maintaining this position.
(C) Starting of an upwards powerfully pulling of the snare and subsequent peeling of the polyp.
(D) Submucosal chord ("nipple" sign) after polypectomy which disappears with air insufflation. 


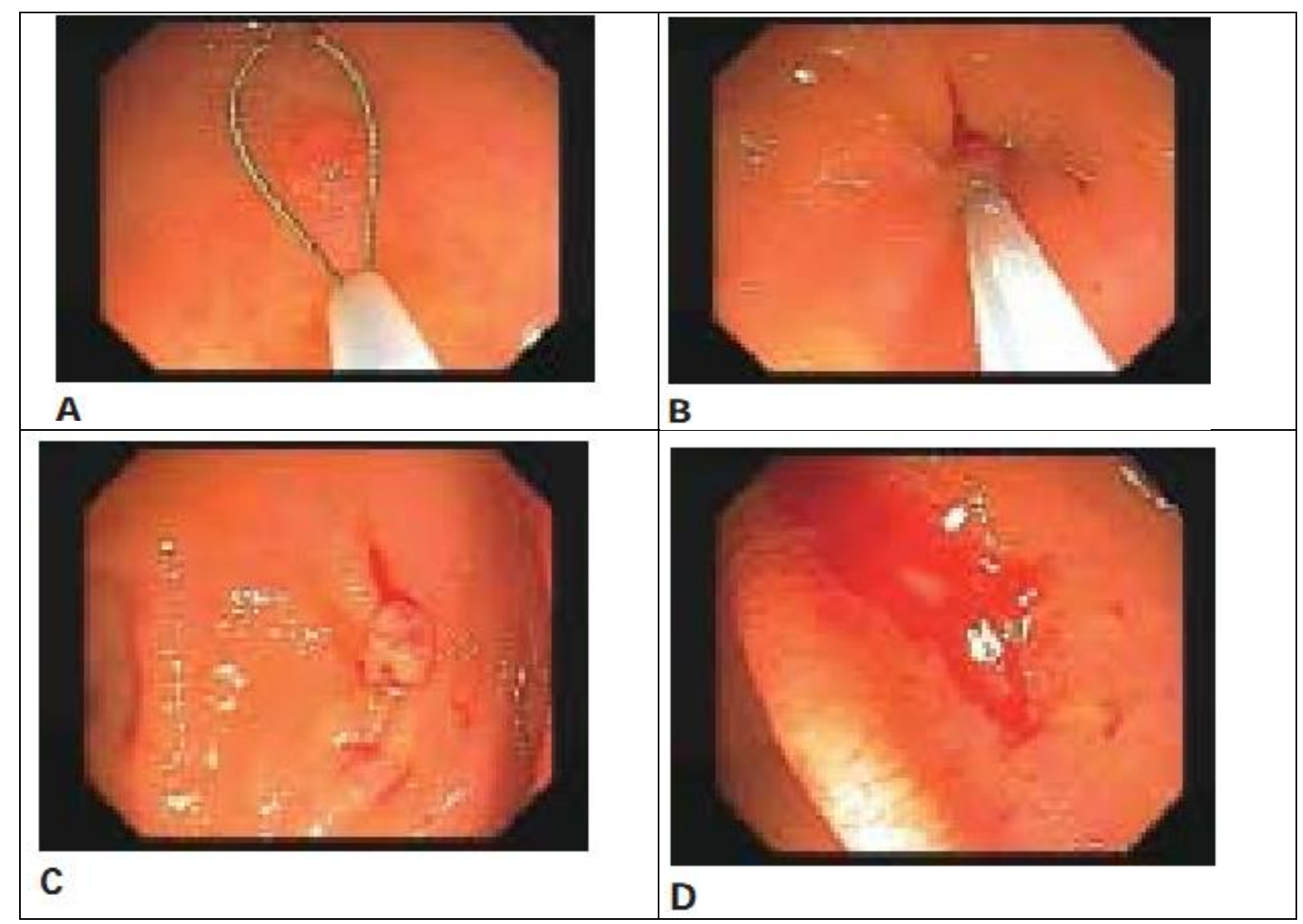

Figure (2): Cold snaring technique. (A) The polyp is grasped in an attempt to ensnare 1-2 mm of normal tissue around the polyp. (B) The polyp is transected without tenting. (C) The polyp remains on the site in nearly all cases. (D) The mucosal defect after suctioning the polyp into a trap.

\section{Hot snare procedure:}

Electrocautery with snare polypectomy is more common for larger polyps. The polyp should optimally be in the 5-7 o'clock position.

(1) The polyp should be tented toward the center of the lumen to stretch the submucosa away from the muscularis propria and serosa.

(2) The duration of energy delivery should be minimized to prevent injury to the wall of the colon.

\section{Cold biopsy forceps procedure:}

For sessile colonic polyps less than $5 \mathrm{~mm}$. The jaws are positioned over the polyp which is grasped, removed, and retrieved. More than one bite may be needed to remove all polypoid tissue.

\section{Follow up and assessments:}

Patients were monitored for complications immediately after the procedure and received a telephone call 14 days later to assess for procedure related complications. Follow up colonoscopy results were available in $90 \%$ of patients at an interval of 3-12 months with 3 months and six months sessions.

\section{Statistical analysis}

Recorded data were analyzed using the statistical package for social sciences, version 20.0 (SPSS Inc., Chicago, Illinois, USA).

Quantitative data were expressed as mean \pm standard deviation (SD). Qualitative data were expressed as frequency and percentage. The following tests were used:

- Independent-samples t-test of significance was used when comparing between two means.

- Chi-square $\left(\mathrm{x}^{2}\right)$ test of significance was used in order to compare proportions between two qualitative parameters.

- The confidence interval was set to $95 \%$ and the margin of error accepted was set to $5 \%$. The p-value was considered significant as following:

- Probability (P-value)

- P-value <0.05 was considered significant.

- P-value <0.001 was considered as highly significant.

- P-value >0.05 was considered insignificant.

\section{RESULTS}

This study included a total of 40 cases with sessile colonic polyps. The age of patients ranged between $20-$ 60 years old with mean age of $31.57 \pm 9.05$ years. 16 (40\%) were males and 24 (60\%) were females. 
The clinical characteristics and indications of endoscopy of patients were lower GI bleeding which may range from occult bleeding detected by fecal occult testing 10 cases $(25 \%)$ or the presence of iron deficiency anemia 4 cases (10\%) to significant lower GI bleeding 20 cases (50\%) and abdominal pain 4 cases $(10 \%)$ (Table 1$)$.

Table (1): Endoscopic characterization of sessile colonic polyps' resection

\begin{tabular}{|l|c|c|}
\hline Variable & $\begin{array}{c}\text { Percent } \\
\text { age }\end{array}$ & $\begin{array}{c}\text { Number of } \\
\text { pts }\end{array}$ \\
\hline Bleeding per rectum & $50 \%$ & 20 \\
\hline Fecal occult blood & $25 \%$ & 10 \\
\hline $\begin{array}{l}\text { Abdominal pain and change } \\
\text { bowel habit }\end{array}$ & $10 \%$ & 4 \\
\hline Iron deficiency anemia & $10 \%$ & 4 \\
\hline $\begin{array}{l}\text { Asymptomatic discovered on } \\
\text { follow up endoscopy }\end{array}$ & $5 \%$ & 2 \\
\hline
\end{tabular}

EMR with mucosal lifting in 14 cases (35\%), hot snare technique in 12 cases (30\%), cold biopsy forceps resection of colonic polyps 10 cases $(25 \%)$ and cold snare technique in 4 cases (10\%). The location of the polyp was most commonly in the cecum/ascending colon $(n=20$ $(50 \%)$ sigmoid colon $(\mathrm{n}=14(35 \%)$ and rectum $(\mathrm{n}=6$ $(15 \%)$. The size of detected sessile polyps were range from 0.5-40 $\mathrm{mm}$ (Table 2).

Table (2): Pathological finding

\begin{tabular}{|c|c|c|c|c|}
\hline Procedure & No/40 & $\%$ & $\begin{array}{l}\text { Median of } \\
\text { size }\end{array}$ & $\begin{array}{l}\text { Range } \\
\text { of size }\end{array}$ \\
\hline $\begin{array}{l}\text { Cold biopsy } \\
\text { forceps }\end{array}$ & 10 & $25 \%$ & 1.1 & $0.5-5 \mathrm{~mm}$ \\
\hline Cold snare & 4 & $10 \%$ & 7.5 & $5-10 \mathrm{~mm}$ \\
\hline Hot snare & 12 & $30 \%$ & 25 & $\begin{array}{c}20- \\
30 \mathrm{~mm}\end{array}$ \\
\hline $\begin{array}{l}\text { EMR with } \\
\text { mucosal lifting }\end{array}$ & 14 & $35 \%$ & 32 & $\begin{array}{c}30- \\
40 \mathrm{~mm}\end{array}$ \\
\hline
\end{tabular}

The polyps removed (including both successful and incomplete resection) included tubular $(\mathrm{n}=18)$, villous $(\mathrm{n}=10)$, and tubulovillous adenomas $(\mathrm{n}=8)$, hyperplastic polyp $(\mathrm{n}=3)$ and serrated adenoma $(\mathrm{n}=1)$ as shown in figure (3).

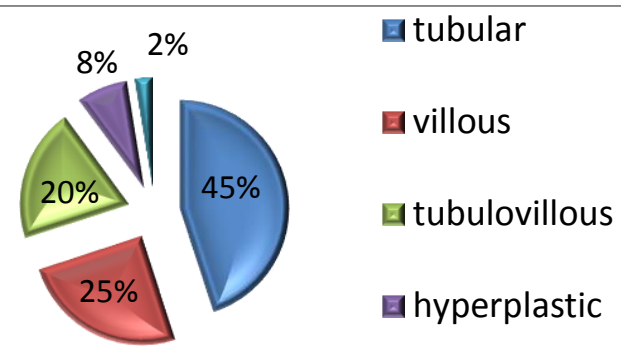

Figure (3): Pathological finding

\section{Complications}

They included nonspecific abdominal pain in 5 patients $(12.5 \%)$ were treated conservatively and bleeding in $3(7.5 \%)$. 1 case presented on $7^{\text {th }}$ day requiring readmission and blood transfusion without any intervention and the other two cases bleeding during procedure that treated effectively with endoscopic clips and electrocautery. In addition, one case transferred into open surgery due to perforation as shown in figure (4).

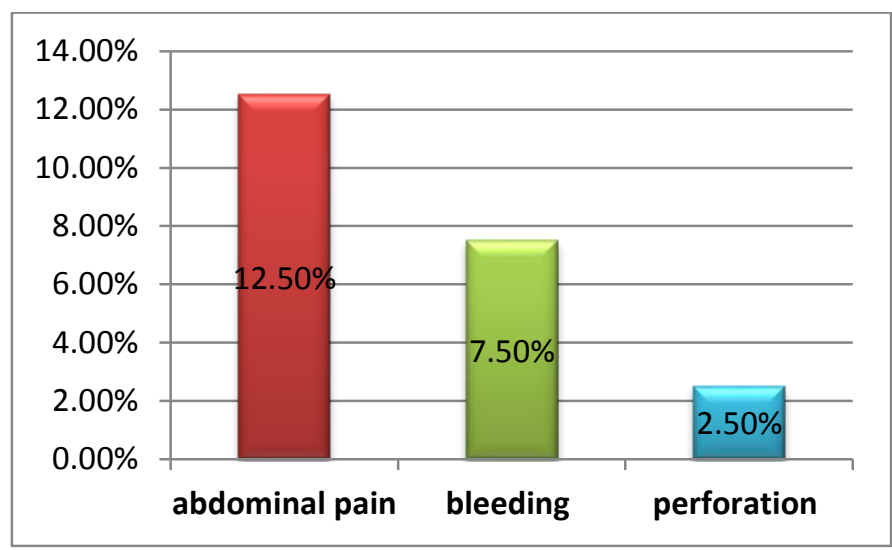

Figure (4): Complications

Table (3): Complete vs incomplete resection

\begin{tabular}{lcc}
\hline Procedure & $\begin{array}{c}\text { Complete } \\
\text { resection }\end{array}$ & $\begin{array}{c}\text { Incomplete } \\
\text { resection }\end{array}$ \\
\hline $\begin{array}{l}\text { Cold forceps } \\
\text { biopsy } \\
\text { Cold snare }\end{array}$ & 10 & - \\
$\begin{array}{l}\text { Hot snare } \\
\text { EMR with } \\
\text { mucosal lifting }\end{array}$ & 12 & - \\
& 13 & $\begin{array}{c}\text { One case } \\
\text { transferred to } \\
\text { surgical } \\
\text { intervention }\end{array}$ \\
\hline
\end{tabular}

\section{DISCUSSION}

Sessile polyps are generally considered to be one of the most difficult polyps to remove endoscopically. Many polyps that might be considered endoscopically respectable are sent for surgical resection. Large sessile polyps are associated with the greatest risk of postpolypectomy bleeding and of perforation. They may take a substantial amount of time to remove ${ }^{(3)}$.

This study included forty patients presented by sessile colonic polyps for endoscopic resection 20 cases came with bleeding per rectum which is considered as most common indication for endoscope that agrees with Hewitson et al. ${ }^{(5)}$.

Complete resection occurred in $97.5 \%$ of polyps, one case $(2.5 \%)$ failed to be resected completely by colonoscopy that referred to surgical interference after perforation occurred during procedure and transverse 
colostomy was done after failed lifting of mucosa by saline injection technique on EMR. EMR with mucosal lifting using saline injection that is available and is relatively inexpensive can be used without any restrictions or concern for chemical or allergic reactions or interactions. However, there are at least 2 main disadvantages. Saline dissipates quickly, and large volumes with frequent injections may be needed for complex and large polyp resections, which increase the procedure time. The submucosal cushion that saline creates typically does not last long, especially when several injections are made into the mucosa and the submucosa, which create multiple "leak" sites ${ }^{(6,7)}$.

Cold snare polypectomy is the preferred resection method for small and diminutive polyps, while hot snare polypectomy and endoscopic mucosal resection (EMR) are recommended for polyps $\geq 10 \mathrm{~mm}^{(8)}$, that agree with this study where we recommend cold snare and cold biopsy forceps for small polyp range from $0.5-10 \mathrm{~mm}$.

In our study bleeding, which is one of the complications of endoscopic resection occurred in 3 of the patients $(7.5 \%)$ this agrees with Hassan et al. ${ }^{(9)}$ who reported that one of clinically important challenges associated with EMR is a higher risk of delayed bleeding, referred to as post EMR bleeding, which occurs in approximately $5 \%$ to $10 \%$ of cases. Typically, within a week of the procedure, patients present with hematochezia that may require hospitalization, blood transfusion and repeat colonoscopy $(\mathbf{9 , 1 0 , 1 1}$ and 12).

Limitations of the study included the limited number of patients and short-term follow-up. Despite these limitations, however, we suggest that it may be reasonable to proceed with endoscopic treatment if the patient is adequately informed of the risks and the endoscopic team is sufficiently experienced.

\section{CONCLUSION}

This study showed that polypectomy of benign sessile colorcctal polyps performed by an expert endoscopist is feasible, effective and safe, even on an outpatient basis. The malignant polyps with incomplete excision, lymphovascular invasion and poor differentiation require bowel resection. Postpolypectomy surveillance is useful for all patients who have undergone colonoscopic resection of giant adenomatous or malignant polyps.

\section{REFERENCES}

1. Burgess NG, Bourke MJ (2016): Endoscopic resection of colorectal lesions: the narrowing divide between East and West. Dig Endosc., 28 (3): 296-305.

2. Endoscopic Classification Review Group (2005): Update on the Paris classification of superficial neoplastic lesions in the digestive tract. Endoscopy, 37 (6): 570-578.

3. Piraka C, Saeed A, Waljee AK et al. (2017): Cold snare polypectomy for non-pedunculated colon polyps greater than $1 \mathrm{~cm}$. Endosc Int Open, 5 (3): 184-189.

4. Fujiya M, Tanaka K, Dokoshi T et al. (2015): Efficacy and adverse events of EMR and endoscopic submucosal dissection for treatment of colon neoplasms: a metaanalysis of studies. Gastrointest Endosc., 81 (3): 583-595.

5. Hewitson $P$, Glasziou $P$, Watson $E$ et al. (2008): Cochrane systematic review of colorectal cancer screening using the fecal occult blood test (hemoccult): an update. Am J Gastroenterol., 103 (6):1541-1549.

6. Uraoka T, Saito $Y$, Yamamoto $K$ et al. (2009): Submucosal injection solution for gastrointestinal tract endoscopic mucosal resection and endoscopic submucosal dissection. Drug Des Devel Ther., 2: 131-138.

7. Repici A, Maselli R, Carrara S et al. (2017): Standard needle versus needleless injection modality: animal study on different fluids for submucosal elevation. Gastrointest Endosc., 86 (3): 553-558.

8. Thoguluva CV, Spadaccini M, Aziz M et al. (2019): Cold snare endoscopic resection of nonpedunculated colorectal polyps larger than $10 \mathrm{~mm}$ : a systematic review and pooledanalysis. Gastrointest Endosc., 89 (5): 929-936.

9. Hassan C, Repici A, Sharma P et al. (2016): Efficacy and safety of endoscopic resection of large colorectal polyps: a systematic review and meta-analysis. Gut, 65 (5): 806-820.

10. Briedigkeit A, Sultanie O, Sido B et al. (2016): Endoscopic mucosal resection of colorectal adenomas $>20 \mathrm{~mm}$ : Risk factors for recurrence. World J Gastrointest Endosc., 8: 276-281.

11. Albeniz E, Fraile M, Ibanez B et al. (2016): A Scoring System to Determine Risk of Delayed Bleeding After Endoscopic Mucosal Resection of Large Colorectal Lesions. Clin Gastroenterol Hepatol., 14: 1140-1147.

12. Qumseya BJ, Wolfsen C, Wang Y et al. (2013): Factors associated with increased bleeding post-endoscopic mucosal resection. J Dig Dis., 14: 140-146. 